\title{
Research on Carbon Emission Scale and Influencing Factors of Green Logistics Industry in Jiangsu, Zhejiang and Shanghai
}

\author{
Fanxin Zeng ${ }^{1}$ \\ ${ }^{1}$ School of Management, Tianjin University of Technology, Tianjin, China.
}

\begin{abstract}
The Jiangsu, Zhejiang and Shanghai areas are important areas for my country's economic development. Its logistics industry is showing a trend of great development, but economic development has also caused considerable pressure on the environment. The paper uses the energy coefficient method to estimate the carbon emissions of the logistics industry in Jiangsu, Zhejiang and Shanghai from 2003 to 2016, and quantitatively analyzes the five factors of energy structure, energy efficiency, industrial structure, economic growth and population. The research results show that the energy structure factors and industrial structure factors in the Jiangsu, Zhejiang and Shanghai regions have a restraining effect on the increase in carbon emissions of the logistics industry, while energy efficiency factors, demographic factors and economic growth factors have an effect on the carbon emissions of the logistics industry. The increase in emissions has a boosting effect. Finally, from the aspects of improving energy efficiency, energy structure, industrial structure, etc., it puts forward specific suggestions and countermeasures for the development of green logistics in Jiangsu, Zhejiang and Shanghai.
\end{abstract}

\section{Introduction}

According to the "China Tertiary Industry Statistical Yearbook 2007", the logistics industry belongs to the tertiary industry, which includes transportation logistics, warehousing logistics, trade logistics, circulation processing and packaging logistics, and postal logistics. Domestic scholars mainly use related mathematical models to measure carbon emissions in the logistics industry and analyze them in different fields. It provides a basis for the estimation of the total carbon emissions of the logistics industry in Jiangsu, Zhejiang and Shanghai and the decomposition of influencing factors.

\section{Estimation of carbon emission scale of logistics industry in Jiangsu, Zhejiang and Shanghai}

\subsection{The carbon emission estimation method of the logistics industry}

At present, there is $\mathrm{CO}_{2}$ nomonitoring data in the logistics industry in the statistical yearbooks of the two provinces and one city in Jiangsu, Zhejiang and Shanghai. This article refers to the research of $\mathrm{Ning}(2015)$, that converts $\mathrm{CO}_{2}$ emissions based on the energy consumption of transportation and warehousing involved in logistics operations. The formula is as follows:

$$
C=\sum_{i=1} C_{i}=\sum_{i=1} \delta_{i} \theta_{i} E_{i}
$$

In the formula: $i$ is the type of energy, $C$ is the total carbon emission, $C_{i}$ is the carbon emission of the i-th energy, $\delta_{i}$ is the carbon emission coefficient of the i-th energy consumed in the various production processes of the logistics industry, and $\theta_{i}$ is the i-th Standard coal conversion factor for energy, $E_{i}$ is the consumption of the i-th energy

\subsection{Calculation results and comparative analysis}

At present, the statistical yearbooks of various provinces do not directly include the energy consumption of the logistics industry, so this article uses the energy consumption of transportation, warehousing and postal industry to express. According to the "China Energy Statistical Yearbook", the energy consumed by the transportation, storage and postal industries in the two provinces and one city in Jiangsu, Zhejiang and Shanghai mainly includes 9 types of raw coal and gasoline. The standard coal conversion coefficient $\left(\theta_{i}\right)$ and carbon emission coefficient $\left(\delta_{i}\right)$ of the energy consumed in the logistics industry operations are shown in Table 1 and Table 2, respectively.

From Table 3, it can be seen that Shanghai, which has the smallest growth rate, was 2.48 times that of 2003 in 2016. In absolute terms, in 2016, for example, Zhejiang was 8.52 million tons, Shanghai was 13.011 million tons, and Jiangsu was 10.8375 million tons. From Table 4, it can be seen that Jiangsu, Zhejiang and Shanghai's logistics

\footnotetext{
* Corresponding author: 1341563287@qq.com
} 
industry has the largest increase in value added from 2003 to 2016. In 2016, the value added of the logistics industry was 3.45 times that of 2003. Judging from the absolute value of the added value of the logistics industry in 2016,
Jiangsu, Shanghai, and Zhejiang were respectively 283.716 billion yuan, 123.732 billion yuan and 177.437 billion yuan in 2016 .

Table 1 Reference coefficients of energy converted into standard coal

\begin{tabular}{|c|c|c|c|c|c|c|c|c|c|}
\hline $\begin{array}{c}\text { energy } \\
\text { species }\end{array}$ & raw coal & gasoline & kerosene & Diesel oil & Fuel oil & $\begin{array}{c}\text { liquefied } \\
\text { petroleum gas }\end{array}$ & natural gas & electricity & heat \\
\hline $\begin{array}{c}\text { coefficient } \\
\left(\theta_{i}\right)\end{array}$ & 0.7143 & 1.4714 & 1.4714 & 1.4571 & 1.4286 & 1.4286 & 1.33 & 0.1229 & 0.0341 \\
\hline
\end{tabular}

Table 2 Carbon emission coefficient of various energy sources

\begin{tabular}{|c|c|}
\hline energy & Factor / ton \\
\hline raw coal & 0.7599 \\
\hline gasoline & 0.5538 \\
\hline kerosene & 0.5714 \\
\hline Diesel oil & 0.5921 \\
\hline Fuel oil & 0.6185 \\
\hline liquefied petroleum gas & 0.5042 \\
\hline natural gas & 0.4483 \\
\hline electricity & 2.2132 \\
\hline Sum & 6.2614 \\
\hline
\end{tabular}

Table 1, Table 2 Data source: IPCC "Guidelines for National Greenhouse Gas Emission Inventories".

Table 3 Carbon emissions and energy consumption of the logistics industry in two provinces and one city from 2003 to 2016

\begin{tabular}{|c|c|c|c|c|c|c|c|c|c|}
\hline \multirow{2}{*}{ years } & \multicolumn{3}{|c|}{ Jiangsu } & \multicolumn{3}{|c|}{ Zhejiang } & \multicolumn{3}{c|}{ Shanghai } \\
\cline { 2 - 10 } & $\begin{array}{c}\text { Energy } \\
\text { conumption }\end{array}$ & $\begin{array}{c}\text { carbon } \\
\text { emission }\end{array}$ & ratio & $\begin{array}{c}\text { Energy } \\
\text { consumption }\end{array}$ & $\begin{array}{c}\text { carbon } \\
\text { emission }\end{array}$ & ratio & $\begin{array}{c}\text { Energy } \\
\text { consumption }\end{array}$ & $\begin{array}{c}\text { carbon } \\
\text { emission }\end{array}$ & \begin{tabular}{c} 
ratio \\
\hline 2003
\end{tabular} \\
\hline 685.21 & 389.88 & 0.57 & 559.84 & 318.70 & 0.57 & 907.45 & 523.86 & 0.58 \\
\hline 2004 & 845.44 & 481.01 & 0.57 & 631.21 & 358.41 & 0.57 & 1204.91 & 685.67 & 0.57 \\
\hline 2005 & 857.89 & 495.30 & 0.58 & 730.16 & 417.31 & 0.57 & 1366.00 & 778.66 & 0.57 \\
\hline 2006 & 937.93 & 526.85 & 0.56 & 834.38 & 476.87 & 0.57 & 1595.97 & 916.32 & 0.57 \\
\hline 2007 & 1027.10 & 576.88 & 0.56 & 923.51 & 527.77 & 0.57 & 1819.18 & 1039.24 & 0.57 \\
\hline 2008 & 1236.59 & 650.69 & 0.53 & 1001.08 & 572.77 & 0.57 & 1884.97 & 1069.59 & 0.57 \\
\hline 2009 & 1287.59 & 677.38 & 0.53 & 1038.05 & 588.98 & 0.57 & 1921.73 & 1078.81 & 0.56 \\
\hline 2010 & 1459.45 & 768.41 & 0.53 & 1197.50 & 637.10 & 0.53 & 1969.65 & 1138.00 & 0.58 \\
\hline 2011 & 1849.56 & 809.66 & 0.44 & 1221.69 & 691.53 & 0.57 & 1967.86 & 1101.53 & 0.56 \\
\hline 2012 & 1953.45 & 879.85 & 0.45 & 1282.78 & 725.38 & 0.57 & 2010.00 & 1120.67 & 0.56 \\
\hline 2013 & 2123.99 & 945.46 & 0.45 & 1343.46 & 758.91 & 0.56 & 2018.35 & 1119.30 & 0.55 \\
\hline 2014 & 2528.43 & 1022.83 & 0.40 & 1373.12 & 773.45 & 0.56 & 2033.62 & 1115.03 & 0.55 \\
\hline 2015 & 2587.79 & 1053.99 & 0.41 & 1399.61 & 821.77 & 0.59 & 2036.41 & 1168.44 & 0.57 \\
\hline 2016 & 2653.40 & 1083.75 & 0.41 & 1423.31 & 825.20 & 0.58 & 2038.21 & 1301.12 & 0.64 \\
\hline
\end{tabular}

Table 4 Summary of added value, GDP and population of logistics industry in Jiangsu, Zhejiang and Shanghai from 2003 to 2016

\begin{tabular}{|c|c|c|c|c|c|c|c|c|c|}
\hline & \multicolumn{3}{|c|}{ Jiangsu } & \multicolumn{3}{c|}{ Shanghai } & \multicolumn{3}{c|}{ Zhejiang } \\
\cline { 2 - 11 } years & $\begin{array}{c}\text { Logistics } \\
\text { industry } \\
\text { increased } \\
\begin{array}{l}\text { Value / 100 } \\
\text { million yuan }\end{array}\end{array}$ & $\begin{array}{c}\text { GDP/ } \\
\text { million } \\
\text { yuan }\end{array}$ & $\begin{array}{c}\text { Total } \\
\text { population } \\
\text { / Ten thousand }\end{array}$ & $\begin{array}{c}\text { Logistics } \\
\text { industry } \\
\text { increased } \\
\text { Value / 100 } \\
\text { million yuan }\end{array}$ & $\begin{array}{c}\text { GDP/ } \\
100 \\
\text { million } \\
\text { yuan }\end{array}$ & $\begin{array}{c}\text { Total } \\
\text { population } \\
\text { / Ten thousand }\end{array}$ & $\begin{array}{c}\text { Logistics } \\
\text { industry } \\
\text { increased } \\
\text { Value / 100 } \\
\text { million yuan }\end{array}$ & $\begin{array}{c}\text { GDP/ } \\
100 \\
\text { million } \\
\text { yuan }\end{array}$ & $\begin{array}{c}\text { Total } \\
\text { population } \\
\text { Ten thousand }\end{array}$ \\
\hline 2003 & 821.48 & 12442.87 & 7458 & 547.81 & 6694.23 & 1766 & 559.07 & 9705.02 & 4857 \\
\hline 2004 & 603.76 & 15003.60 & 7523 & 493.60 & 8072.83 & 1835 & 444.65 & 11648.70 & 4925 \\
\hline 2005 & 798.11 & 18598.69 & 7588 & 571.57 & 9247.66 & 1890 & 513.74 & 13417.68 & 4991 \\
\hline 2006 & 953.57 & 21742.05 & 7656 & 643.92 & 10572.24 & 1964 & 635.16 & 15718.47 & 5072 \\
\hline 2007 & 1101.18 & 26018.48 & 7723 & 682.84 & 12494.01 & 2064 & 748.61 & 18753.73 & 5155 \\
\hline 2008 & 1346.26 & 30981.98 & 7762 & 712.99 & 14069.86 & 2141 & 843.20 & 21462.69 & 5212 \\
\hline
\end{tabular}




\begin{tabular}{|l|l|l|l|l|l|l|l|l|l|}
\hline 2009 & 1423.25 & 34457.30 & 7810 & 635.01 & 15046.45 & 2210 & 888.02 & 22990.35 & 5276 \\
\hline 2010 & 1768.30 & 41425.48 & 7869 & 834.40 & 17165.98 & 2303 & 1076.67 & 27722.31 & 5447 \\
\hline 2011 & 2127.93 & 49110.27 & 7899 & 868.31 & 19195.69 & 2347 & 1206.95 & 32318.85 & 5463 \\
\hline 2012 & 2352.40 & 54058.22 & 7920 & 895.31 & 20181.72 & 2380 & 1278.91 & 34665.33 & 5477 \\
\hline 2013 & 2425.11 & 59753.37 & 7939 & 935.91 & 21818.15 & 2415 & 1427.52 & 37756.59 & 5498 \\
\hline 2014 & 2591.15 & 65088.32 & 7960 & 1044.46 & 23567.70 & 2426 & 1525.93 & 40173.03 & 5508 \\
\hline 2015 & 2705.44 & 70116.38 & 7976 & 1133.17 & 25123.45 & 2415 & 1631.88 & 42886.49 & 5539 \\
\hline 2016 & 2837.16 & 77388.28 & 7999 & 1237.32 & 28178.65 & 2420 & 1774.37 & 47251.36 & 5590 \\
\hline
\end{tabular}

\section{Influencing factors of carbon emissions from the logistics industry in Jiangsu, Zhejiang and Shanghai}

The data on the added value, GDP, and permanent population of the logistics industry in the Jiangsu, Zhejiang and Shanghai regions in this article are all taken from the statistical yearbooks of the provinces. The carbon emissions data in the logistics industry comes from the previous calculations of energy consumption. Therefore, the five aspects of energy structure, energy efficiency, industrial structure, economic development, and demographic factors have become important factors affecting the increase of carbon emissions in the logistics industry(De and Kaneko ,2011). According to the previous calculation formula, using the 2003 data as the base, the decomposition results of the factors affecting the increase in carbon emissions of the logistics industry in the two provinces and one city in Jiangsu, Zhejiang and Shanghai were calculated (Papagiannaki and Diakoulaki, 2009).

\subsection{Energy structure factors}

From the perspective of the entire Jiangsu, Zhejiang and Shanghai regions, Zhejiang's energy structure factors have led to an increase in carbon emissions from the logistics industry. The remaining two provinces basically showed a restraining effect that is conducive to reducing carbon emissions. The other two provinces consumed various oil energy during the observation period. The amount is increasing year by year, but at the same time, the consumption of relatively low-polluting energy such as natural gas and electricity is also increasing year by year. In contrast, Zhejiang, in 2003-2016, the consumption of gasoline, kerosene, diesel, and fuel oil increased year by year. The use of clean energy is the main reason for the difference in energy structure factors between Zhejiang and the other two provinces. It shows that the improvement of modern logistics efficiency is conducive to the reduction of carbon emissions while promoting rapid economic growth.

\subsection{Energy efficiency factors}

From the perspective of the entire Jiangsu, Zhejiang and Shanghai regions, energy efficiency factors in Jiangsu and Shanghai during the observation period played a role in promoting the increase in carbon emissions of the logistics industry, but the role of Jiangsu and Shanghai in promoting carbon emissions showed a steady downward trend, while Zhejiang was a restraint (Qu et al. 2019). Among the two provinces and one city, Zhejiang's energy efficiency factors inhibited the most significant increase in carbon emissions. Energy efficiency depends on the renewal of equipment, management mode and many other factors. As the entire Internet economy center, Zhejiang is a cluster of science and technology and universities, which can improve energy efficiency and reduce carbon emissions.

\subsection{Industrial structure factors}

From the perspective of the entire Jiangsu, Zhejiang and Shanghai regions, industrial structure factors reflect the proportion of the logistics industry in the total economic output. The fluctuation and trend of this ratio express the problem of optimizing the industrial structure of two provinces and one city in Jiangsu, Zhejiang and Shanghai. For Jiangsu and Shanghai, the ratio is showing a downward trend, and the industrial structure of Jiangsu and Shanghai is optimizing year by year.

\subsection{Economic development factors and demographic factors}

From the perspective of the entire Jiangsu, Zhejiang and Shanghai regions, the increase in carbon emissions due to economic development in the two provinces and cities of Jiangsu, Zhejiang and Shanghai is due to the increase in economic levels, factors such as car ownership, travel, express parcels and other residents, and the continuous increase in industrial production capacity. Factors lead to.

\section{Suggestions for low-carbon development of logistics industry in Jiangsu, Zhejiang and Shanghai}

Promote clean energy and optimize the energy structure. It can be seen from the above research that the energy structure can effectively reduce carbon emissions. The rapid economic development will lead to the development of animal flows, and at the same time will produce a large amount of carbon emissions, and clean energy such as natural gas can effectively improve the energy structure, thereby reducing carbon emissions. On the one hand, it is necessary to increase energy sources such as natural gas with low carbon emission factors, improve their utilization 
efficiency, and gradually reduce the utilization rate of energy sources with high carbon emission factors such as coal and oil. On the other hand, it is necessary to continuously develop clean energy sources such as wind and solar energy. In the choice of transportation means, new energy vehicles can also be used to gradually replace fuel vehicles to control the number of high-emission trucks in the logistics industry from the source. Develop low-carbon logistics and optimize energy efficiency ( Luo et al.2019). The optimization of the industrial structure and the improvement of energy efficiency are all conducive to reducing carbon emissions. The development of modern logistics industry can effectively integrate relevant logistics resources, change the situation of original enterprises self-run logistics and independent management, and help reduce carbon emissions as a whole. Logistics companies should strengthen the R\&D and application of low-carbon technologies such as green transportation and green warehousing, continuously improve energy efficiency, research and develop new energy, and improve transportation efficiency through measures such as intermodal transportation and logistics integration, and gradually reduce carbon emissions to achieve low logistics (Du and Jia,2017).Carbonization development. The government will promote low-carbon economy and low-carbon logistics development so that logistics industry practitioners understand the significance of low-carbon development in the logistics industry, strengthen the supervision of logistics enterprises' carbon emissions, and guide logistics enterprises to adopt lowcarbon technologies and develop low-carbon logistics

\section{Conclusion}

The Jiangsu, Zhejiang and Shanghai regions are an important area of my country's economic development. The implementation of national policies and natural location advantages have provided convenient conditions for the logistics industry in the region, but at the same time it has also brought huge carbon emissions to the environment and rapid economic development. Among the five factors, the two provinces and one city in Jiangsu, Zhejiang and Shanghai have the greatest impact on the carbon emissions of the logistics industry. Among them, the energy structure has a limited impact on the carbon emissions of the logistics industry in Jiangsu, Zhejiang and Shanghai, and almost remains at a constant level. The higher the energy efficiency, the slower the growth rate of carbon emissions, and the stronger the inhibitory effect of energy efficiency factors on the growth of carbon emissions. Structural factors have shown a restraining effect on the increase in carbon emissions of the logistics industry in Jiangsu, Zhejiang and Shanghai, and have gradually increased during the observation period. Economic development factors have greatly promoted the carbon emissions of the logistics industry in Jiangsu, Zhejiang and Shanghai, and Shanghai has the smallest growth rate.

\section{References:}

1. Ning Ningning. Regional logistics carbon emissions differences and influencing factors analysis [D]. Tianjin: Tianjin University of Technology, 2015.

2. De Freitas L C, Kaneko S. Decomposing the decoupling ofCO2 emissions and economic growth in Brazil [J]. Ecological Economics, 2011, 70 ( 8): 14591469.

3. Papagiannaki K, Diakoulaki D. Decomposition analysis of $\mathrm{CO} 2$ emissions from passenger cars: The cases of Greece and Denmark [J]. Energy Policy, 2009, 37(8): 3259-3267.

4. Qu Fuqiang, Chen Chuyi, Yan Wei. Quality Risk Assessment of Prefabricated Building Components Based on ANP-FUZZY[J]. Journal of Civil Engineering and Management, 2019, 36(03):92-98.

5. Luo L, Shen G Q, Xu G, et al. Stakeholder Associated Supply Chain Risks and Their Interactions in a Prefabricated Building Project in Hong Kong[J]. Journal of Management in Engineering, 2019, 35(2):94-107.

6. Du Yunzhou, Jia Liangding. Configuration perspective and qualitative comparative analysis (QCA): a new way of management research[J]. Management World, 2017(06):155-167. 